\title{
STUDY OF HEALTH PROBLEMS AND HEALTH RELATED SOCIAL FACTORS IN GERIATRIC POPULATION AT UHC AREA OF S N MEDICAL COLLEGE, BAGALKOT
}

B. S. Mannapur, K. R. Kulkarni, Pavan S. Kalasker.
1. Associate Professor. Department of Community Medicine, S. Nijalingappa Medical College, Bagalkot, Karnataka.
2. Assistant Professor/Statistician. Department of Community Medicine, S. Nijalingappa Medical College, Bagalkot, Karnataka.
3. Post Graduate Student, S. Nijalingappa Medical College, Bagalkot, Karnataka

\section{CORRESPONDING AUTHOR}

Dr. Basavaraj S. Mannapur,

Department of Community Medicine,

S. Nijalingappa Medical College,

Bagalkot-587102, Karnataka.

E-mail: drbasu_m@rediffmail.com

Ph: 00919448182921

\begin{abstract}
BACKGROUND: A major emerging demographic issue of $21^{\text {st }}$ century is the ageing of the population as an inevitable consequence of demographic transition experienced by most countries. Change in socio-economic status and various health problems adversely affect an individual's way of life during old age. Objective: To study the health problems and health related social factors of the elderly in an urban health centre area. Methodology: The study was conducted in Urban Health Centre area of S.N.Medical College, Bagalkot .The total population of UHC was 4500 covering six Anganwadis. All the people who were 60 years and above were studied in that area, who were 244 in all. Study design and variables: A Cross-sectional study. A pretested, structured questionnaire was used to collect information by house to house interview method on Socio-demographic factors and health related factors. Results: The mean age of the study population was $67.0 \pm 14.7$ (Mean \pm 2 SD). Majority (44.7\%) of geriatric population belonged to the age group of $60-64$ years.62.3\% were females. Around one third $(36.1 \%)$ of them were illiterate. Half (50\%) of the elderly were housewives. $44.3 \%$ belonged to lower socio-economic status. $46.3 \%$ of the study population was having hypertension. $32 \%$ of the aged complained of locomotors problems such as joint pain \& other musculoskeletal problems. $19.3 \%$ of the study population was having a habit of tobacco chewing. Main interfamily problem was related to economic status (27.5\%). 29.9\% of the elderly solved their problems themselves. Majority (80.7\%) of them preferred to stay with their son followed by daughter (7\%). $64.3 \%$ of the aged spends time by looking after their house. Conclusion: The main health problems among the elderly were hypertension and locomotors system related problems. The social factors associated with elderly were, habits such as tobacco chewing, main reason for interfamily problem was economic related. Therefore elderly people need care and support from the family members and society.
\end{abstract}

KEYWORDS: Geriatric population, Urban area, Health problems, Social factors

INTRODUCTION: Ageing, a biological phenomenon is a global issue with its implications on population, infrastructure, social issues, finances and health. The world is graying and so is India. Currently pegged at around $8 \%$ of our population. The Indian elderly are projected to 
constitute around $21 \%$ of our population by 2050 . For the developing countries including India, the ageing population may pose mounting pressures on various socio-economic fronts including health care expenditures. For such countries the social and economic consequences of ageing could harsh and the options for diluting the adverse effects of grey population may be limited. ${ }^{1}$

Ageing of populations and extension of life are significant by-products of the demographic transition. Ageing of population is primarily the result of two factors, reductions in fertility and mortality. The reduction in mortality rates implies a longer life span for the individual and the reduction of fertility implies a decline in the proportion of the young in the total population. Thus an 'ageing population' means a population characterized by higher average life expectancy and increasing proportion of the elderly in the total population. ${ }^{2}$

Old age can be broadly characterized by time-altered changes in an individual's biological, psychological and health related capabilities and its implications for the consequent changes in the individual's role in the economy and the society. This immediately implies that there are a vast number of issues that call for an attentive focus on the elderly. ${ }^{3}$ The best course is to 'Grow old gracefully or at least gracefully accept that we are growing old'. ${ }^{4}$ Longer and much advanced age need more intensive and long term care, which in turn may increase financial stress in the family. Inadequate income is a major problem of elderly in India. ${ }^{5}$

The aged, living in retirement, not only suffer from chronic diseases but also from the unhappiness caused by their feeling of uselessness, loneliness \& despair. This makes it necessary to look into the various aspects of their problems like social, economic, and psychological and other related aspects. ${ }^{6}$

Hence, this study was taken up with the objective of assessing the health status and social factors among the elderly with a view to improve our health care services for them.

OBJECTIVE: To study the health problems and health related social factors of the elderly in an urban area.

METHODOLOGY: The study was conducted in Urban Health Centre area of Dept. of Community Medicine which is located $6 \mathrm{Km}$ away from S.N.Medical College; Bagalkot. The total population of UHC was 4500 covering six Anganwadis.

Study Subjects: The United nation defined 60 years as the age of transition of people to the elderly segment of the population. In India $60^{\text {th }}$ year is conventionally taken as the pointing old. ${ }^{7}$ All the people who were above 60 years were 244 . The elderly who couldn't be interviewed during the first round were interviewed during second round and elderly still remaining uninterviewed were contacted during third round in-order to obtain maximum coverage. Informed consent was taken.

Study Period: From January 1 to June 30, 2009 over a period of six months. Study design and variables: A Cross-sectional study. The pretesting of the proforma was done on 50 elderly persons to test the factors like time required to collecting the information from each elderly and clarity of questions and feasibility of study. A pretested, structured questionnaire was used to collect information by house to house personal interview method on socio-demographic factors, health related factors. Blood pressure was measured using standard Sphygmomanometer in a sitting position. Blood Pressure classification was done based on seventh report of the Joint National Committee ${ }^{8}$ 


\begin{tabular}{lll}
\hline Blood pressure classification & SBP $(\mathbf{m m H g})$ & DBP $(\mathbf{m m H g})$ \\
\hline Normal & $<120$ & $<80$ \\
Pre-hypertension & $120-139$ & $80-89$ \\
Stage I hypertension & $140-159$ & $90-99$ \\
Stage II hypertension & $\geq 160$ & $\geq 100$ \\
\hline
\end{tabular}

General physical examination was done. Data was tabulated \& analyzed and findings were described using proportions \& percentage.

RESULTS: The mean age of the study population was $67.01 \pm 14.6$ (Mean \pm 2 SD). Majority $(44.7 \%)$ of the aged belonged to the age group of $60-64$ years and $23.8 \%$ belonged to $65-69$ years. $62.3 \%$ were females. $36.1 \%$ of the elderly were illiterate. Half $(50 \%)$ of the elderly were housewives by occupation followed by businessmen (16.8\%). Majority of the elderly belonged to the socio-economic class V (44.3\%) and IV (34.0\%).

$46.3 \%$ of the study population was having hypertension. Among the hypertensive's, $36.5 \%$ were in pre-hypertension stage, nearly one third (34.4\%) of them were in stage I and $11.9 \%$ in stage II of hypertension.

The next major health problem was locomotors (32\%) in the form of Joint pain, myalgia and musculoskeletal problems. $13.5 \%$ of aged were suffering from Diabetes. The other health problems in the elderly were Diminished vision, Respiratory problems and hearing problems.

$19.3 \%$ of the study population was having a habit of tobacco chewing in the form of ghutka, tobacco and pan. Tobacco smoking was present in $8.2 \%$.The main reason for interfamily problem was economic (27.5\%) related. $29.9 \%$ of the elderly people used to solve family problems by themselves. $34.8 \%$ and $27.5 \%$ of them solved by discussing with their son \& spouse respectively. Majority (80.7\%) of them preferred to stay with their son followed by daughter (7\%). Only $4.5 \%$ of them were staying alone. Majority (64.3\%) spends time by looking after their house and $13.1 \%$ with their young ones. Others were involved in agriculture, labour . $4.5 \%$ were not involved in any kind of work. $48.4 \%$ of the aged felt that, there is necessity of old age homes in their area.

DISCUSSION: In this study, conducted in urban area among elderly, majority (44.7\%) was in the age group of 60-64 years and the mean age was 67 years. Similar observations were made by A. J. Purty et al. ${ }^{9}$ that is the mean age was 67.1 years and the largest age group was $60-64(41.8 \%)$ years old. It is observed in this study that, $37.7 \%$ were males and $62.30 \%$ were females. A study carried out by Rajashree Bhatt et al. ${ }^{10}$ reported almost similar results that is $33.9 \%$ were male \& $66.1 \%$ were female.

In our study, $36.1 \%$ of the elderly were illiterate, $31.6 \%$ had studied upto primary school and only $6.1 \%$ were college \& above. According to the NSS 52 nd round, $1163 \%$ of the elderly were illiterate in India (Gupta I). Padda, et al. ${ }^{12}$ reported 38.6\% illiteracy at Amritsar which is in accordance with our study, in contrast it was $78 \%$ in a study conducted in Tamil Nadu by Elango, ${ }^{13}$ and Singh, et al. ${ }^{14}$ reported $80.2 \%$.

In our urban study area, half (50\%) of the elderly were housewives and $16.8 \%$ were businessmen by occupation. In a study conducted by Purty AJ et al. ${ }^{9}$ the predominant occupation was agricultural labour $64.7 \%$ as the study was conducted in rural area. Niranjan GV 
et al. ${ }^{15}$ found that $46.2 \%$ of the geriatric population belonged to the social class-III whereas in this study, majority of the elderly belonged to the socio-economic class V (44.3\%) and IV (34\%).

It was found in this study that $46.3 \%$ of the elderly were having hypertension. Among the hypertensive's, $36.5 \%$ were in pre-hypertension stage, nearly one third (34.4\%) of them were in stage I and $11.9 \%$ in stage II of hypertension.. A study carried out by Rajashree et al $^{10}$ reported almost similar findings i.e., 34.4\% were having hypertension and were classified as prehypertension (43.1\%), stage I (30.7\% ) \& stage II (9.6). In HM Swami et al ${ }^{16}$ study, most common diseases in order of their magnitude were hypertension (58\%) joint pains/arthritis $(50.5 \%)$ cataract $(19.1 \%)$, gastritis (17.7), deafness $(13.5 \%)$ followed by diabetes mellitus (12.2\%). In the present study, the most common health problems of the elderly were Hypertension (46.3\%), locomotors system related (32\%), diminished vision $(13.9 \%)$ and respiratory problems(14.3). A.S Padda etal ${ }^{12}$ revealed that, Arthritis (60.6\%) being the commonest cause of illness followed by cataract or visual impairment (54\%). 16.6\% of the aged were hypertensive which is less when compared to our study.

$19.3 \%$ of the elderly were having a habit of tobacco chewing in this study. Tobacco smoking was present in $8.2 \%$. Bala etal. ${ }^{17}$ in their study of tobacco use in Gujarat state found in age group of 65 years or older $10.68 \%$ were tobacco chewer and $64.7 \%$ were smokers. The main reason for interfamily problem was economic (27.5\%) related. Unlike our study, Singh, et al. ${ }^{14}$ reported that the main reason for feeling sad was loneliness $(20 \%)$, followed by neglect in the family (26.1\%), illness (11.5\%), and economic causes $(10.2 \%)$. Majority $(80.7 \%)$ of them preferred to stay with their son followed by daughter (7\%). Srivastava \& Mishra's ${ }^{18}$ revealed that the majority of elderly were found living with their spouse \& other member. Majority (64.3\%) spends time by looking after their house. while Singh, et al. ${ }^{14}$ in his study, reported that $55.8 \%$ were occupied in productive work, $28 \%$ in agriculture, $15.1 \%$ in labor, and $44.2 \%$ were dependent on others.

CONCLUSION: The present study in the urban area has identified common health problems such as Hypertension, locomotors system related problems, diabetes, diminished vision and respiratory problems. The study also revealed tobacco chewing as the main habit, economic problem as the main interfamily problem. Most of them solved their family problems by themselves and by discussing with their spouse. There is an urgent need to develop geriatric health care services in the developing countries like India and provide training to health care providers to manage the commonly existing health problems in the community.

\section{REFERENCES:}

1. Shankar PS, Jali MV. Advances in Geriatrics, First edition. KLEA's Prabhakar Kore Hospital and MRC National Diabetes foundation, Belgaum, 2012; 1.

2. Siva Raju S. Ageing in India: An Overview. IN, Gerontological Social Work in India:Some Issues and perspectives, Edited by Murli Desai and Siva raju. Delhi: B.R. Publishing Corporation, 2000; 27-58.

3. Irudaya, Rajan S and U.S.Misra. Defining Old Age: An Indian Assessment. Bold.1995 Vol. 5: 4.

4. Garg BS, Gupta SC. growing old gracefully, Swasthhind March-April 1982; 26(3-4): 5758. 
5. Siva Raju, S. "Meeting the Needs of the Poor and Excluded in India', Situation and Voices. The Older Poor and Excluded in South Africa and India, UNFPA, Population and Development Strategies, 2002; 2: 93-110

6. Editorial: The problems of the aged. Indian Journal of public health April-June 1979;23 (2):61-62.

7. ICMR-Mental health \& ageing. ICMR bulletin, May 1991; 21 (5): 49-54.

8. The seventh report of the joint national committee on prevention, detection, evaluation and treatment of high blood pressure. JAMA 2003; 289:2560-71.

9. A. J. Purty, J. Bazroy, M. Kar, K. Vasudevan, A. Veliath, P. Panda. Morbidity Pattern Among the Elderly Population in the Rural Area of Tamil Nadu, India. Turk J Med Sci.2006;36: 45-50.

10. Rajshree Bhat1, Minal S Gadhvi, K N Sonaliya, Anand Solanki, Himanshu Nayak. An Epidemiological Study of the Morbidity Pattern among the Elderly Population in Ahmedabad, Gujarat. National Journal of Community Medicine. July-Sept 2011; Vol 2 Issue 2: 233-236.

11. Gupta I, Sankar D. Health of the elderly in India: a multivariate analysis. Journal of Health \& Population in Developing Countries / URL: http://www.jhpdc.unc.edu/Date Published 24 June, 2003 p1-11. http://www.iegindia.org/dis_ind_46.pdf

12. Padda AS, Mohan V, Singh J, Deepti SS, Singh G, Dhillon HS. Health Profile of aged persons in urban and rural field practice areas of Medical College Amritsar. Indian J Community Med 1998; 23:72-6.

13. Elango S. A study of health and health related social problems in the Geriatric population in a rural area of Tamil Nadu. Indian J Public Health 1998; 42:7-8.

14. Singh C, Mathur JS, Mishra VN, Singh JV, Singh RB, Garg BS. Social Problems of Aged in a rural population. Indian J Community Med 1994;19:23-5.

15. 1Niranjan GV, Vasundhra MK. A study of health status of aged persons in slums of urban field practice area, Bangalore. Indian J Com Med 21:1-4, 1996.

16. Swami HM, Vikas Bhatia, Rekha Dutt, Bhatia SP Bahrain Medical Bulletin, Vol.24, No.1, March 2002.

17. Bala DV, Bodiwala I, Patel DD, Shah PM, Epidemiological determinants of Tabasco use in Gujarat state IJCM 2006; 31(3): 173-76.)

18. Srivatava $\mathrm{H} \mathrm{C}$, Mishra $\mathrm{N}$ R, Living arrangement \& morbidity pattern among elderly in rural India. International Institute for population science Mumbai 2005: 1-7.

Table 1: Socio-demographic profile of study population

\begin{tabular}{lrc}
\hline Category & No. & \% (N=244) \\
\hline Age & 109 & 44.7 \\
$60-64$ & 58 & 23.8 \\
$65-69$ & 36 & 14.7 \\
$70-74$ & 22 & 9.0 \\
$75-79$ & 19 & 7.8 \\
$80+$ & & \\
Gender & 92 & 37.7 \\
Male & 152 & 62.3 \\
Female & &
\end{tabular}




\begin{tabular}{lrr}
\hline \hline & & 36.1 \\
Illiterate & 77 & 31.6 \\
Primary school & 39 & 16.0 \\
Middle school & 25 & 10.2 \\
High school & 15 & 6.1 \\
College \& above & & \\
Occupation & 07 & 2.9 \\
Farmer & 32 & 13.1 \\
Labor & 122 & 50.0 \\
Housewife & 41 & 16.8 \\
Business & 22 & 9.0 \\
Skilled workers & 20 & 8.2 \\
Others & & \\
Socio-economic class & 03 & 1.2 \\
Class I & 16 & 6.6 \\
Class II & 34 & 13.9 \\
Class III & 83 & 34.0 \\
Class IV & 108 & \\
Class V & & \\
&
\end{tabular}

Table 2: Health problems and Hypertensive status of the aged

\begin{tabular}{|c|c|c|}
\hline Health problem (Multi-response) & No. & $\%$ \\
\hline Hypertension & 113 & 46.3 \\
\hline Locomotors & 78 & 32.0 \\
\hline Diabetes & 33 & 13.5 \\
\hline Diminished vision & 34 & 13.9 \\
\hline Respiratory problems & 35 & 14.3 \\
\hline Hearing problems & 06 & 2.5 \\
\hline IHD & 04 & 1.6 \\
\hline Others & 24 & 9.8 \\
\hline Hypertensive status ( $\mathrm{N}=244)$ & No. & $\%$ \\
\hline Normal & 42 & 17.2 \\
\hline Pre-hypertension & 89 & 36.5 \\
\hline Stage I & 84 & 34.4 \\
\hline Stage II & 29 & 11.9 \\
\hline
\end{tabular}

Table 3: Social problems of the elderly

\begin{tabular}{lcr}
\hline Social problems & No. $(\mathbf{N}=244)$ & \% \\
\hline & & \\
Habits & & \\
Tobacco smoking (Bidi \& cigarette) & 20 & 8.2 \\
Tobacco Chewing (Tobacco, Gutka \& Pan) & 47 & 49.3 \\
Alcohol & 12 & 4.9 \\
No habits & 165 & 67.6
\end{tabular}




\section{Reason for Interfamily problems}

Economic

Marriage

Education \& employment

Property

Illness

No problems

Solving family problems

Self

Spouse

Son

Others

Prefer to stay with

Son

Daughter

Brother

Alone

Others

Spends time by looking after

Agriculture

House

Young one's

Labor

Others

Nil
67

27.5

02.0

02.0

02.5

0.8

65.2

29.9

27.5

34.8

07.8

80.7

7.0

03.3

04.5

04.5

$\begin{array}{rr}12 & 04.9 \\ 157 & 64.3 \\ 32 & 13.1 \\ 14 & 05.8 \\ 18 & 07.4 \\ 11 & 04.5\end{array}$

